\title{
Olhares Sobre as Vivências de Profissionais Que Atuam com Cuidados Paliativos em Hospitais
}

\author{
Views on Experiences of Professionals who Work with Palliative Care in Hospitals \\ Miradas Sobre las Vivencias de Profesionales que Actúan con Cuidados Paliativos en \\ Hospitales
}

\author{
Eloisa Capeletto ${ }^{1}$ \\ Denise Vieira Taborda \\ Ana Caroline Birr \\ Mikeller Freire de Lima \\ Sofia Cieslak Zimath \\ Universidade da Região de Joinville (Univille)
}

\begin{abstract}
Resumo
Esta pesquisa, exploratória e qualitativa, teve como objetivo compreender as vivências de profissionais que prestam cuidados paliativos (CP) em hospitais de Joinville, considerando sua formação acadêmica. Por CP, entendem-se ações que visam à qualidade de vida daqueles que estão diante de uma doença terminal. Para a coleta de dados, realizaram-se entrevistas semiestruturadas e não diretivas com seis profissionais, sendo: três psicólogas, uma capelã hospitalar, uma fisioterapeuta e uma enfermeira. A partir da análise de conteúdo das entrevistas, averiguou-se que existe uma falha da graduação quanto ao debate do processo de morte e morrer, a qual se manifesta na dificuldade de comunicação, no excesso ou falta de sensibilidade e resistência presentes na prestação dos CP. Além disso, verificou-se que diálogos sobre a morte são tabus e envoltos por uma série de emoções e sentimentos complexos que necessitam ser discutidos.
\end{abstract}

Palavras-chave: capacitação profissional, cuidados paliativos, morte, pessoal de saúde

\begin{abstract}
This exploratory and qualitative research has as objective to understand the experiences of health professionals that provide palliative care (CP) at hospitals of the city of Joinville, considering their formation. Palliative care are actions that aim at quality of life for those who are facing a terminal illness. To collect the data, were done semi-structured and non-directive interviews, with six professionals: three psychologists, a hospital chaplain, a physiotherapist, and a nurse. From the content analysis of the interviews, it was verified that, in the education of the professionals, there is a graduation failure regarding the discussion of the death and dying process, which is manifested in the difficulty of communication, in the excess or lack of sensitivity and resistance present in the provision of palliative care. In addition, it is understood that dialogues about death are taboo and are involved by a series of complex emotions and feelings that need to be discussed.
\end{abstract}

Keywords: professional training, palliative care, death, health personnel

\section{Resumen}

Esta investigación, exploratoria y cualitativa, tuvo como objetivo comprender las vivencias de profesionales que prestan cuidados paliativos en hospitales de Joinville, considerando su formación académica. Por cuidados paliativos, se entienden acciones para la calidad de vida de aquellos que están ante una enfermedad terminal. Para la recolección de datos, se realizaron entrevistas semiestructuradas y no directivas con seis profesionales, siendo: tres psicólogas, una capellán de hospital, una fisioterapeuta y una enfermera. A partir del análisis de contenido de las entrevistas, se averiguó la existencia de una falla de la graduación en cuanto al debate del proceso de muerte y morir, la cual se manifiesta en la dificultad de comunicación, en el exceso o falta de sensibilidad y resistencia presentes en la prestación de los cuidados paliativos. Además, se verificó que los diálogos sobre la muerte son tabús y envueltos por una serie de emociones y sentimientos complejos que necesitan ser discutidos.

Palabras clave: capacitación profesional, cuidados paliativos, muerte, personal de salud

\footnotetext{
${ }^{1}$ Endereço de contato: Rua João Remi de Lima Meirelles, 402, Garuva, SC, CEP: 89248-000. E-mail: eloisacapeletto@gmail.com
} 


\section{Introdução}

Diante de uma doença crônica e terminal, pensar sobre a morte se torna inevitável, visto que essas situações colocam o indivíduo em contato com a sua fragilidade, finitude e impotência. Assim, profissionais que convivem com pacientes em estágios finais de vida necessitam estar preparados para vivenciar a impotência e angústia perante uma condição irreversível, na qual se encara um sujeito repleto de sentimentos e emoções conflitantes. Para isso, a educação na saúde se faz importante, uma vez que ela abrange a sistematização de conhecimentos para a atuação em saúde, envolvendo práticas de ensino, diretrizes didáticas e orientação curricular, indo além dos aspectos tecnicistas oferecidos na educação formal (Falkenberg, Mendes, Moraes, \& Souza, 2014).

É parte da natureza humana temer o fim da vida, assim como a vida vegetativa, ainda que lhes sejam oferecidos cuidados de alta qualidade (Mabtum \& Marchetto, 2015). Dessa forma, questões relacionadas aos Cuidados Paliativos (CP) e formas de morrer são pautadas com base em concepções religiosas, filosóficas e culturais, as quais geram visões multifacetadas que, por conseguinte, dificultam a decisão do sujeito quanto a prolongar ou dar um fim à própria vida (Batista, 2006; Mabtum \& Marchetto, 2015). As decisões finais devem diferenciar os procedimentos médicos que resultam numa vida com qualidade daqueles que apenas levam ao sofrimento, sem nenhuma perspectiva de melhora ou cura (Porto \& Lustosa, 2010; Mabtum \& Marchetto, 2015).

Entre os procedimentos, há: eutanásia, que consiste na escolha pelo suicídio enquanto o indivíduo está consciente ou inconsciente, fato que difere do suicídio assistido, em que o sujeito necessariamente deve estar cônscio (Siqueira-Batista \& Schramm, 2004); distanásia, que seria a obstinação ou futilidade terapêutica, promovendo a manutenção da vida por meio de tratamentos desproporcionais (Martin, 1998; Mabtum \& Marchetto, 2015); ortotanásia, prática que não apressa e nem prolonga o processo de morrer, mas proporciona condições de vida durante esse período, aliviando o sofrimento; e mistanásia, que seria a morte miserável fora e antes do seu tempo. Alguns autores a denominam de eutanásia social, tendo em vista a relação íntima que o fenômeno tem com a maldade humana (Porto \& Lustosa, 2010).

Para além desses conceitos, destaca-se os CP, que, para a Academia Nacional de Cuidados Paliativos (ANCP, 2006), referem-se aos cuidados prestados a pacientes com doença progressiva e irreversível, atentando-se ao controle da dor e de outros sintomas por meio da prevenção e do alívio do sofrimento físico, psicológico, social e espiritual. Esses cuidados devem ser prestados a partir do momento do diagnóstico de uma doença potencialmente fatal, adaptando-se às necessidades dos pacientes, bem como às suas famílias, na medida em que a doença progride para a fase terminal (World Health Organization [WHO], 2007).

Para um paciente ser incluído em um programa de CP, existem escalas que podem ser preenchidas pelo próprio paciente, por um familiar ou pela equipe multiprofissional. É importante que sejam utilizadas mais de uma escala, porque cada uma mede aspectos específicos, que podem ser pautados nos sintomas e na evolução da doença, no comprometimento funcional ou na qualidade de vida do paciente. Diante dessas informações, destacam-se duas escalas: a Palliative Care Screening Tool (PCST) e a Escala de Performance de Karnofsky (EPK). Os instrumentos são úteis na identificação de problemas de saúde, na tomada de 
decisão e no monitoramento das alterações do estado de saúde dos pacientes ou na resposta ao tratamento (Marcucci, 2016).

O Center to Advance Palliative Care, de acordo com Marcucci, Perilla, Brun e Cabrera (2016), desenvolveu um documento que sugere o uso da escala PCST para a triagem de pacientes em programas de CP. Essa escala visa considerar a necessidade ou não de CP com base em uma graduação numérica predefinida. A PCST estabelece a pontuação de acordo com a presença de doenças primárias e secundárias que ameaçam a sobrevivência, a qualidade de vida e a funcionalidade (Marcucci et al., 2016).

A EPK também pode ser utilizada para avaliar a capacidade e dependência funcional (Marcucci, 2016). Ela avalia a capacidade funcional em um escore que varia de 0 a 100 e considera que a menor pontuação resulta em maior comprometimento funcional. Pacientes com escore inferior a 70 têm indicação precoce de CP, e aqueles com pontuação inferior a 50 pontos, isto é, que passam mais da metade do dia sentados ou deitados e que necessitam de cuidados médicos constantes, são incluídos nos programas de CP (Marcucci et al., 2016; Marcucci, 2016).

Considerando os profissionais que prestam CP, em uma abordagem interdisciplinar - médico, enfermeiro, fisioterapeuta, terapeuta ocupacional, fonoaudiólogo, orientador espiritual, técnico de enfermagem, cuidador formal, psicólogo etc. -, frisa-se o papel da psicologia, tendo em vista as necessidades clínicas e psicossociais dos pacientes e suas famílias, incluindo aconselhamento e suporte ao luto (Costa, Poles, \& Silva, 2016).

Diante da terminalidade humana, o psicólogo busca a qualidade de vida do paciente, amenizando seu sofrimento, ansiedade e depressão diante da morte. Sua atuação ocorre tanto no nível de prevenção quanto nas diversas etapas do tratamento, e ela não se limita ao paciente, mas deve incluir toda a família, auxiliando-os a falar sobre a doença, fornecendoIhes as informações necessárias ao tratamento, contribuindo na elaboração de um processo que ajudará o paciente a enfrentar a doença e construindo experiências de adoecimento, processo de morte e luto (Hermes \& Lamarca, 2013).

Dito isso, e visando compreender a vivência de profissionais da saúde que prestam CP em hospitais de Joinville, foram entrevistadas três psicólogas, uma enfermeira e uma fisioterapeuta. Além dessas, uma capelã hospitalar também participou da pesquisa. A capelania hospitalar não compõe o quadro de profissões da saúde que são definidas na Portaria n. 174, de 27 de janeiro de 2006 (Brasil, 2006), porém tem regulamentação institucional. Buscou-se, ainda, apresentar a importância da compreensão dos CP na educação formal e continuada desses profissionais, bem como conhecer os principais desafios que surgem à equipe multiprofissional de cada hospital, ponderando as habilidades e os conhecimentos necessários para a prestação dos CP e discutindo de que forma as instituições de ensino podem contribuir para o avanço na formação em CP.

\section{Método}

O objetivo desta pesquisa foi verificar a compreensão da vivência de profissionais da saúde que prestam CP em hospitais de Joinville, considerando a educação permanente e continuada envolvida na formação deles. Para isso, utilizou-se de uma abordagem qualitativa e do método da pesquisa exploratória. A pesquisa exploratória visa ao aprimoramento de ideias. Nesse tipo de pesquisa, geralmente se utilizam entrevistas com pessoas que tiveram 
experiências com os fenômenos estudados. Na abordagem qualitativa, há uma sequência de atividades: redução dos dados, categorização, interpretação e redação de um relatório (Marconi \& Lakatos, 2003; Gil, 2010).

Para a coleta de dados, foram realizadas entrevistas semiestruturadas e não diretivas, com seis profissionais de dois hospitais privados do município de Joinville que prestam CP, sendo: três psicólogas, uma capelã hospitalar, uma fisioterapeuta e uma enfermeira. As entrevistas ocorreram no próprio local de trabalho das profissionais, em uma sala de reunião disponibilizada pelas instituições.

Por entrevista semiestruturada, entende-se aquela com um roteiro previamente elaborado, apoiado em teorias e hipóteses que interessam à pesquisa e, em seguida, oferecem amplo campo de interrogativas, fruto de novas hipóteses que vão surgindo na medida em que se recebem as informações dos participantes (Trivinos, 1987). O roteiro de entrevista semiestruturada foi composto por 12 questões que versaram sobre os seguintes tópicos: dados gerais de identificação do participante, definição de CP, como começou a trabalhar com $\mathrm{CP}$, formação continuada e permanente em CP, dia a dia no hospital e funções, dificuldades presentes na prestação dos CP, como lida com as reações do paciente diante da iminência de morte, formação acadêmica e CP, critérios utilizados na instituição para incluir um paciente no programa de CP, papel e a reação do grupo de amigos e familiares do paciente diante do $\mathrm{CP}$, como os CP podem ser considerados uma estratégia de humanização do atendimento e, por fim, como os CP poderiam ser trabalhados na formação.

A seleção da amostragem da pesquisa define-se como de conveniência e não probabilística. Esse tipo de amostra, segundo Shaughnessy, Zechmeister e Zechmeister (2012), envolve a seleção de respondentes com base na sua disponibilidade e disposição para responder.

Faz-se importante ressaltar que os participantes da pesquisa tiveram seu anonimato preservado, mediante a assinatura do Termo de Consentimento Livre e Esclarecido (TCLE) e do Termo de Autorização de Uso de Imagem e/ou Voz. A pesquisa somente teve início após aprovação no Comitê de Ética em Pesquisa da Universidade da Região de Joinville (Univille), sob parecer de número 2.195.431, de 10 de agosto de 2017.

A entrevista se deu a partir de gravação de voz e anotação das reações não verbais das entrevistadas, e tal material, posteriormente, foi transcrito na íntegra. As linhas transcritas de cada entrevista foram sequencialmente numeradas para facilitar a análise dos dados. Os locais foram identificados por letras ( $A$ e B) e as participantes por números, estando assim descritas: 1A (fisioterapeuta), 2A (psicóloga), 3A (capelã hospitalar), 1B (enfermeira), 2B (psicóloga) e 3B (psicóloga).

O método para analisar os resultados obtidos pela entrevista foi a análise de conteúdo proposta por Franco (2012), cujo ponto de partida "é a mensagem, seja ela verbal (oral ou escrita), gestual, silenciosa, figurativa, documental ou diretamente provocada" (p. 12). Para Marconi e Lakatos (2003), essa análise refere-se ao processo de conhecimento de determinada realidade e implica o exame sistemático dos elementos, permitindo observar os componentes de um conjunto e perceber suas possíveis relações. Entretanto, segundo Franco (2012), devese considerar que a emissão de mensagens está "necessariamente vinculada às condições contextuais de seus produtores. Nesse sentido, a Análise de Conteúdo assenta-se nos pressupostos de uma concepção crítica e dinâmica da linguagem" (p. 13). Portanto, na análise de conteúdo, deve ser principalmente interpretado o sentido que um indivíduo atribui às mensagens. 


\section{Resultados e Discussão}

\section{Definições de cuidados paliativos e critérios de inclusão}

As entrevistadas $1 \mathrm{~A}$ e $2 \mathrm{~A}$ concordam ao afirmarem que $\mathrm{CP}$ são aqueles cuidados que se têm com a qualidade de vida e bem-estar do indivíduo no presente, minimizando seus sofrimentos físicos e emocionais. Os CP, por sua vez, não estão aliados à cura e também não se desvinculam de dedicação, amor e paixão. A entrevistada 2A ainda declara que, se o cuidado não estiver em primeiro lugar, não há possibilidade de existir $C P$, o qual, de acordo com 3A, deve primar uma visão holística da vida do paciente. A importância do cuidado e do respeito ao próximo pode ser observada na fala de $2 \mathrm{~A}$ :

É muito mais fácil a gente entender sofrimento quando tem uma ferida aberta . . . Mas o que que tá doendo? Não sou eu que tô sentindo, não tenho que sentir dor, mas que sofrimento é esse? Sofrimento de perda de dignidade, sofrimento de tá usando uma fralda, sofrimento de tá com mau hálito, sofrimento de tá com mau cheiro de uma ferida, isso também é dor, né? Então minimizar todos esses sofrimentos é o nosso papel e trabalhar isso junto com a equipe faz parte dos cuidados paliativos.

As definições de CP trazidas pelas participantes alinham-se a alguns princípios da OMS, como aquele que frisa a importância de proporcionar alívio à dor e a outros sintomas, meIhorar a qualidade de vida do paciente e, também, influenciar positivamente o curso da doença (WHO, 2007).

Para 1B, trata-se de uma abordagem de cuidados integrais em que vários profissionais atuam, no sentido de garantir uma terminalidade digna, definiria os CP. Já para 2B, OS CP constituem "mais do que um modo de trabalho, ... é uma filosofia". Ainda segundo a entrevistada, os CP se caracterizam como um programa que visa prestar o atendimento para o paciente com o intuito de proporcionar, de maneira integral, uma vida com qualidade, por meio do suporte emocional, controle de sintomas, controle de dor, alívio espiritual e suporte à família nos dias que restam àquele paciente, sejam eles quantos forem.

Percebe-se, na fala das entrevistadas, o respeito à dignidade humana e a sensibilidade na promoção de qualidade nos últimos momentos de vida do indivíduo, o que vai ao encontro da definição de CP colocada por Mabtum e Marchetto (2015): "o direito à morte digna consiste em respeitar a autonomia do indivíduo, sua personalidade, seus valores, sua concepção de vida e morte" (p. 61).

No que se refere à inclusão de um paciente no programa de cuidados paliativos, a entrevistada 2A traz a informação de que é um diagnóstico médico que define esse quesito. Dessa forma, quando o médico entende que foram esgotadas as possibilidades de tratamento de manutenção ou prolongamento da vida, parte-se do princípio de que o paciente entrou em CP. A partir disso, pode haver uma série de protocolos. Entre esses protocolos, estão as escalas que foram citadas na fundamentação teórica deste artigo: a PCST e a EPK.

Dito isso, a ANCP (2009) afirma que a inclusão de um paciente em CP envolve julgamentos fisiológicos e sociais bastante complexos. Por isso, essa avaliação busca reforços constantes em sinais, sintomas e escalas que podem identificar o processo de morte em fases precoces.

No hospital em que a entrevistada $2 \mathrm{~A}$ atua, existe uma ferramenta que oficializa a entrada do paciente em CP e, nesse momento, toda a equipe multidisciplinar passa a fornecer 
um cuidado com esse foco. Sabe-se que, até pela OMS, é preconizado que os CP tenham início concomitante ao do cuidado curativo, a partir do momento que existe o diagnóstico da doença crônica, incurável e limitadora da vida. Logo, não deveria existir um ponto para determinar onde parou o tratamento curativo e iniciaram-se os CP. São duas linhas que vão seguindo até o momento em que uma vai perdendo força, porque o espectro de possibilidades diminui. Frisa-se aqui que, quando um paciente está em CP, não se deixa de tratar a doença crônica e outras doenças eventuais, até porque existem enfermidades que são crônicas e que convivem com o paciente por muito tempo, como é o caso da diabetes. A ANCP (2009), entretanto, afirma que, se o critério estabelecido pela OMS fosse obrigatoriamente cumprido, a maioria dos pacientes, mesmo assim, permaneceria sem assistência paliativa, visto que não há disponibilidade de profissionais e serviços que possam dar conta da demanda existente.

Nesse sentido, a entrevistada $1 \mathrm{~A}$ acrescenta que, de maneira geral, os pacientes que entram em CP já estão em fase terminal, os quais vêm a falecer dentro de poucos dias ou semanas. Entretanto, já tendo conhecimento da patologia do paciente que está sendo acompanhado, a equipe multidisciplinar passa a olhá-lo e assisti-lo de maneira diferente, mesmo que ele ainda não esteja oficialmente em CP.

Numa perspectiva variada, as entrevistadas 1B e 2B trazem informações sobre o trabalho na atenção domiciliar, em que os pacientes deixam o ambiente hospitalar e migram para o tratamento em seu próprio domicílio. Nesses casos, eles já se encontram em estado terminal, sem quaisquer possibilidades curativas. No hospital em que ambas trabalham, existem diversos casos de falecimento em domicílio, sendo que tal situação é trabalhada com o paciente e sua família. Apoiando-se nisso, são ponderadas as escolhas e os rituais de término de vida do paciente, além das abordagens que ele deseja para suas horas finais e para após a sua morte. A ANCP (2009) alega que a maioria dos pacientes, com enfermidades em fase terminal, deseja morrer em sua casa na presença de seus familiares, sem dispensar a prevenção e o alívio de sofrimento e o tratamento de dor ou outros problemas físicos, psicológicos, sociais e espirituais.

A entrevistada 2B também comenta sobre o programa de acolhimento pós-morte, que é entendido como parte dos CP. Assim, a prestação dos cuidados não termina quando o paciente falece, pois existe o estabelecimento de um vínculo com a família. Assim, é feito o acolhimento e rastreamento do luto complicado após o falecimento do paciente para os familiares e cuidadores. Além disso, 3A traz que, devido a sua função de capelã hospitalar, ela realiza o acolhimento junto de sua equipe até a funerária chegar, oferecendo suporte necessário à família enlutada.

\section{Dificuldades presentes na prestação dos cuidados paliativos}

Quando questionadas sobre as dificuldades presentes na prestação de CP, as entrevistadas consideram a comunicação como ponto importante para o desenvolvimento e manejo do trabalho. De acordo com Andrade, Costa e Lopes (2013), por meio da comunicação adequada, é possível reconhecer e acolher, de forma empática, as necessidades do paciente e de seus familiares. A comunicação é, portanto, considerada fundamental na prestação do cuidado integral e humanizado. 
Entretanto, apenas as participantes 1B e 2B citaram o termo "falhas na comunicação". Como forma de exemplificar a importância do diálogo e de como palavras mal colocadas, ou até mesmo eufemismos, podem distorcer o significado de uma mensagem, 3B relata uma situação em

... que o enfermeiro. . comunicou assim: "Seu pai foi a óbito". "Ah, tá. Em qual setor, então, que posso ir lá ver ele?". A pessoa não entendeu que ele tinha morrido. "Ah, seu pai fez a passagem". "Ah, pra que setor ele fez a passagem?". Então, poder ajudar os profissionais a dizer "morreu", "nós morremos", a morte está aí, ela existe e antes dela acontecer poder tá também conversando a questão de perdoar e perdoar-se, faz uma grande diferença, até pela qualidade daquele momento de partida, aquele momento onde que eu deixo de respirar.

Sendo assim, ao se refletir sobre as habilidades e conhecimentos necessários para a prestação dos CP, considerando a relação com o paciente e seus familiares, é unânime entre as entrevistadas a ideia de que, para que estes entendam a situação, o profissional da saúde é diretamente responsável por abordar os esclarecimentos acerca dela. A comunicação, assim, deve ser clara e direta, como aponta a entrevistada 2B: "Quanto mais claro, quanto mais próximo e quanto mais confiança houver entre equipe e grupo familiar e paciente, mais tranquilo, mais fácil e mais fluido vai ser, mais saudável vai acontecer". A participante 3A, dentro dessa perspectiva, destaca a importância de realizar uma abordagem detalhada e sem muitos termos técnicos, o que pode propiciar um maior entendimento acerca do que são os CP.

A entrevistada 3A complementa ao afirmar que, caso não seja explicado aos familiares e amigos o real objetivo dos $\mathrm{CP}$, pode ser que fique a ideia de que a equipe multidisciplinar não vai fazer mais nada a respeito do paciente. Também, a participante 2B aponta a necessidade de esclarecer aos familiares e amigos conceitos como a ortotanásia e distanásia, explanados ao longo deste artigo por Martin (1998), Porto e Lustosa (2010) e Mabtum e Marchetto (2015).

Outro ponto levantado pelas entrevistadas diz respeito à dificuldade em fazer com que a própria equipe entenda o que é realmente CP. Nesse sentido, 2B comenta sobre a prevalência do curar sobre o cuidar, sobretudo, na formação médica. Para ela, "muitas vezes os profissionais ainda têm muita resistência. . . de encarar esse paradigma que tem mudado de uma busca de cura e tratamentos a qualquer custo para uma abordagem mais focada no alívio e na qualidade de vida". Confirma 2A esse padrão, ao dizer que a formação médica é um modelo biológico. "É tratar para curar, se não for pra curar não tem o que tratar, né?". Infelizmente, é comum a entrevistada ouvir de outros profissionais a frase: "Não tem mais o que fazer". Enquanto profissional, ela entende que essas pessoas se referem a não ter mais recursos curativos. Todavia, o paciente que ouve essa frase conclui que:

... vai ser relegado, que não vai ser feito nada, que ele tá sendo desistido, que ele vai ficar desassistido. . . então, essa é uma frase que tem que ser. . abolida do vocabulário do profissional, ... até porque que ela não é verdadeira. . se for pra pensar em questão de trabalho, o paciente em cuidados paliativos, ele vai dar mais trabalho que o outro paciente, né? (2A)

Para além da interlocução, o desafio no trabalho em CP, segundo 3A, reside na dificuldade de todos os seres humanos em lidar com a terminalidade, pois a morte é "algo que nós não 
temos poder". O não falar sobre a morte nas instituições reforça essa dificuldade. A entrevistada $1 \mathrm{~A}$ também relata um bloqueio pessoal para lidar com as emoções e sentimentos desencadeados quando um paciente de longa data falece. Nesses casos, ela afirma que: "Você vai sofrer, você vai sentir, você vai sofrer com os familiares, você vai chorar junto". A entrevistada 3B ressalta a importância do autocontrole sobre as emoções para suportar o trabalho dentro do hospital. Ela aponta que é necessário, ao profissional da psicologia, fazer psicoterapia e ter algum lazer no qual possa aliviar a sobrecarga emocional, pois sofrer junto do paciente consome muita energia do profissional. Por isso, é importante manter o equilíbrio:

. . . eu não posso sofrer ao ponto de não conseguir cuidar, e nem me tornar insensivel ao ponto de cuidar como se fosse uma coisa, né? Banalizar o cuidado, então, eu acho que hoje em dia essa é a maior dificuldade quando a gente fala de cuidado paliativo: é a questão da humanidade dos profissionais de uma forma geral, né? Todos eles. (2A).

Esslinger (2004 citado por Porto \& Lustosa, 2010), acerca de tal situação, aponta que, a partir do momento que os profissionais de saúde entram em contato com seus sentimentos ao prestar tais cuidados, estes podem identificar-se e, por meio disto, terão a chance de entrar em contato com as necessidades, os desejos e sentimentos do paciente.

A insensibilidade de alguns profissionais pode refletir em um cuidar não adequado que, conforme a entrevistada $2 \mathrm{~A}$, pode ser projetado com violência ao ". . . não atender a campainha, demorar. . . Ou às vezes a postura física, ou uma palavra mal colocada quando vai fazer o cuidado". Nesse sentido, há dois extremos: os profissionais que banalizam o cuidado e aqueles muito sensíveis, que adoecem ao lidar com o sofrimento.

\section{Cuidados paliativos como estratégia de humanização}

As entrevistadas dão ênfase à humanização do cuidar e ao olhar diferenciado para com os pacientes. O conceito de humanização, de acordo com Silveira, Ciampone e Gutierrez (2014), permeia o "ato de humanizar, dar condição humana a, humanar, civilizar, tornar-se humano, humanar-se" (p. 11). Diz respeito, portanto, à presença da essência humana no cuidar, sendo ele o suporte da criatividade, da liberdade e da inteligência, que são transpassados pelos princípios, valores e atitudes presentes na ação e na vivência (Silveira et al., 2014). Para 2A, se não houver a humanização, os CP se realizam apenas como uma técnica, uma especialidade médica, como mais um serviço oferecido pelos hospitais. Faz-se necessário, portanto, um cuidado humanizado para que se criem estratégias que venham a oferecer conforto em uma situação em que nenhuma palavra ou ação sejam suficientes para trazer tranquilidade.

Nesse segmento, a entrevistada $2 \mathrm{~A}$ relata casos em que condutas e posturas não usuais foram utilizadas para garantir prazeres a pacientes com pouca expectativa de vida. Ela refere a necessidade de amor ao próximo para levar um médico a realizar uma gastrostomia, com o objetivo de permitir ao paciente etilista, em estado terminal, tomar a sua cachaça. Ser sensível à dor do outro também permite a criação de um meio para que um paciente possa tocar em seu animal de estimação, pela última vez, em uma visita hospitalar.

Ainda de acordo com 2A, o paciente em CP demanda criatividade da equipe multiprofissional, mediante a utilização de medicamentos off label, para minimizar sintomas e ferramentas que Ihe proporcionem harmonia. Segundo Ramos e Ferreira (2013), medicamentos off label referem-se àquelas prescrições cuja indicação, faixa etária, dose ou via de 
administração não estão incluídas nas informações da bula. Esse tipo de prescrição requer grande responsabilidade técnica e ética do profissional, que deve prever os riscos e benefícios para cada paciente. Percebe-se então a indispensabilidade de um médico formado e especializado em CP, o qual deve entender de medicamentos não usuais.

Dito isso, a entrevistada $2 \mathrm{~B}$ reflete sobre a importância desses comportamentos, que estão diretamente ligados ao acolhimento daquele paciente em padecimento. Ela afirma:

Eu acredito no poder do acolhimento; de estar ao lado do paciente; de poder fazer esse holding; de poder realmente segurar o paciente. Quando a gente consegue acolher, a gente consegue ter empatia com ele. Se a gente tem empatia, então a gente vai buscar os princípios básicos do cuidado paliativo, que é o alívio dos sintomas, a busca de intervenções que não sejam invasivas, a busca da qualidade de vida e do conforto espiritual, familiar, comunitário.

Essas considerações condizem com os conceitos apresentados pela ANCP (2006), no qual se nota a ocorrência da paliação e ação paliativa em decorrência da não efetivação da futilidade terapêutica, que prolonga o sofrimento do paciente e, até mesmo, sua morte.

Essa forma de cuidar humanizada típica dos CP necessitaria se presentificar em toda forma de tratamento e procedimento. A entrevistada 3B atenta para o fato de que quaisquer pacientes deveriam ser tratados com respeito, tendo a assistência de um profissional que dá atenção a sua dor, aos seus sintomas e ao seu sofrimento. Daí entende-se a ponderação das entrevistadas $2 \mathrm{~A}$ e $3 \mathrm{~A}$ ao afirmarem que os CP não são uma estratégia de humanização, mas sim uma consequência dela. Uma vez que "Se nós não conseguimos exercer a humanização desde aquele paciente que só veio aqui pra extrair uma unha, né, não adianta lá pegar o cuidado paliativo pra trazer a humanização" (3A). A entrevistada 3B reforça esta ótica ao verbalizar:

. . . isso deveria ser uma premissa para qualquer pessoa, não só pra quem tá numa situação de não ter mais possibilidade de cura para sua patologia, né? [Em] Qualquer paciente que entra no hospital deveria ser olhado todo esse aspecto psicossocial, né?

Quando se trabalha em um hospital, é preciso estar preparado para lidar com a dor do outro. Conforme a entrevistada 3B, "Tirando as cirurgias plásticas e o nascimento, todo mundo que está aqui, está aqui porque está sofrendo [. . .]". O sofrimento do outro, por si só, deveria ser suficiente para que o profissional da saúde deixasse de ser apenas humano e passasse a ser um humano humanizado (3A).

A humanização estende-se para além do paciente e engloba as pessoas que o acompanham em todo o processo de terminalidade. Assim, a entrevistada 2B expõe a necessidade de:

... dar todo o suporte, de telefone; para quem ele vai ligar; como é que ele vai se organizar; quem ele vai chamar se o paciente falecer; chamar SOS; ligar para o nosso setor ou para funerária; para que eles se organizem em relação a isso, para que as coisas fiquem um pouco mais claras. Quando a gente torna o estranho mais familiar, as coisas ficam mais fáceis de lidar. 
Essa mesma ótica aplica-se quando a entrevistada $1 \mathrm{~A}$ aponta para a flexibilidade no atendimento dos pacientes em CP. Dentro disso, ela relata o fato de se conceder ao paciente um acompanhante a mais, e que aquele acompanhante também tenha direito à alimentação no hospital.

\section{Os Cuidados Paliativos e a Educação na Saúde}

As profissionais entrevistadas relatam a escassez de informações relacionadas aos CP durante o período da graduação. Nesse sentido, 2A e 3B declaram que a sua formação em psicologia foi voltada para a prática clínica, sendo banalizada a área hospitalar. Quanto aos CP, $2 \mathrm{~A}$ afirma que tal abordagem nem era comentada na época em que ela estava na graduação; $3 \mathrm{~B}$ até cita que em alguns momentos os $\mathrm{CP}$ foram discutidos, mas de maneira muito superficial. A entrevistada 2B, por sua vez, afirma que teve a disciplina de psicologia hospitalar, na qual houve contato com os $\mathrm{CP}$, além das aulas de ética que também abordaram o tema. Ela expõe ainda que a academia, de maneira geral, não dá o devido espaço para falar sobre o processo de morrer, pois são discutidas, na grande maioria do tempo, as fases iniciais e intermediárias do desenvolvimento, enquanto a velhice ocupa pouco tempo da graduação.

As participantes $1 \mathrm{~A}, 1 \mathrm{~B}$ e $3 \mathrm{~A}$ alegam não ter visto o tema $\mathrm{CP}$ em sua graduação, e que seus conhecimentos sobre o assunto derivam da experiência profissional dentro do hospital e de cursos de educação continuada. Complementando, a entrevistada $2 \mathrm{~A}$ verbaliza que o cuidado acontece, mesmo na área da enfermagem, que seria aquela destinada essencialmente ao cuidar como técnicas, e não um processo humanizado, por conta do modelo biomédico que se segue. $3 \mathrm{~A}$ afirma ainda que, no final de sua formação, começaram a aparecer livros acerca da morte e do morrer. Ela enfatiza que os acadêmicos de teologia tinham preparação para sepultar, mas não para acompanhar o processo de morte e morrer.

Para a entrevistada 2A, os CP dentro da formação acadêmica poderiam ser trabalhados de uma forma mais dinâmica, devendo-se enfocar a comunicação, pois o processo envolve uma rede extensa de indivíduos (paciente e família, paciente e equipe, família e equipe, equipe e equipe). Ela aponta ainda a importância de se ter uma capelã hospitalar na equipe de seu local de trabalho, pois a psicologia não aborda questões relacionadas à espiritualidade, uma vez que muitos confundem esse termo com a religiosidade, e, como religiosidade não é ciência, ela não está no escopo do psicólogo. Assim, podem ser trabalhadas as emoções envolvidas em relação à terminalidade, bem como o suporte aos pacientes e familiares que necessitam desse apoio espiritual, o que se enquadra no exposto por Hermes e Lamarca (2013), que afirmam que as ações do psicólogo dentro dos CP devem incluir a família, auxiliando aspectos diversos que permeiam a construção de experiências de adoecimento, processo de morte e luto.

Ainda para 2A, o papel do psicólogo é relacionado, principalmente, com a equipe. A equipe a qual ela se refere não se restringe apenas a profissionais da área da saúde, mas engloba outros, como os que trabalham na recepção, na copa, com a higienização do hospital etc. Durante o levantamento teórico que embasou este artigo, pouco se encontrou sobre a integração do psicólogo com a equipe, sendo tal temática explorada por Esslinger (2004 citado por Porto \& Lustosa, 2010). Ele refere à importância do psicólogo para a equipe de saúde que presta $\mathrm{CP}$, afirmando que, quando os profissionais se deparam com pacientes 
sem possibilidades terapêuticas, podem se identificar e, assim, entrar em contato com as necessidades, desejos e sentimentos do paciente. Alinhando ao que afirma a ANCP (2012), é importante que o psicólogo realize essa troca com profissionais de outras áreas para que possa ter clareza sobre os seus limites dentro do campo de trabalho, realizando intervenções eficientes.

Para a entrevistada 1B, é importante que se fale sobre a questão da terminalidade durante a formação dos profissionais para que, no exercício da profissão, seja possível realizar uma abordagem de qualidade. A entrevistada 2B afirma também que é importante falar sobre tais questões para que os futuros profissionais já tenham uma noção sobre os $\mathrm{CP}$, e sugere que sejam estimuladas as formações continuadas e permanentes dentro das instituições de ensino.

Sugere 3B que esse assunto seja trabalhado já na infância, pois se fosse explicado às crianças que a morte é um processo natural, e que todos vão passar por ele, seria muito mais fácil lidar com tal situação posteriormente. Ela afirma ainda que a morte e o morrer deveriam ser temas obrigatórios em todo curso da área da saúde, visto que a maior dificuldade dos profissionais formados é lidar com a terminalidade.

A entrevistada 3A também destaca a importância de se falar com as crianças sobre a morte, quando declara: "Nós estamos com uma grande dificuldade com a finitude humana, porque nós nos iludimos achando que, não levando crianças pra visitar pessoas em terminalidade no hospital, vai fazer muito bem pra sociedade".

Neste aspecto, deve-se colocar em pauta o fato de o tema morte ser ainda um tabu, não somente nos espaços acadêmicos, mas em todos os âmbitos da vida. Essa afirmação pode ser confirmada pela fala da entrevistada 3B:

... deveria ser falado sobre isso em casa, hoje em dia isso virou um tabu em todos os lugares e até no hospital, né? Então tem pessoas que trabalham com a saúde, e chega aqui e 'ai meu deus, mas morre tanta gente!', e se impacta com isso, é a algo que faz parte da vida, né?

Aguiar et al. (2006) acreditam que profissionais da área da saúde devem estar preparados para vivenciar sentimentos e situações que os pacientes demandam. Ademais, os autores concordam quanto à deficiência na formação acadêmica desses profissionais, enfatizando ainda que, muitas vezes, apenas o curar é visto como uma boa prática dentro desta área, e que a morte é sinônimo de falha.

\section{Considerações Finais}

Diálogos sobre a morte e o morrer são vetados e envoltos por uma série de emoções e sentimentos complexos. Mesmo nos hospitais - espaço considerado por muitos como um local de sofrimento -, falar sobre a finitude da vida humana é uma situação delicada e geralmente destinada apenas a profissionais da psicologia. A comunicação, assim, sobressai como um ponto fundamental na prestação dos CP, a qual possibilita o esclarecimento de certos argumentos e demandas contraditórias. Dito isso, propõe-se levantar considerações acerca das hipóteses iniciais levantadas nesta pesquisa e os dados coletados.

Uma das hipóteses era de que os profissionais da área da saúde evidenciavam apenas o curar e a parte técnica da profissão. Esta pôde ser refutada em parte, visto que, durante o 
estudo, as entrevistadas demonstram ter uma atenção para além daquilo que lhes é exigido quanto ao desempenho técnico de suas funções. Entretanto, os relatos que demonstram a insensibilidade, o despreparo e a banalização do cuidar por parte de alguns profissionais, que atuam nos hospitais, não permitem a negação total da hipótese.

Percebeu-se concomitantemente a falta de discussões sobre a morte e o processo que dela decorre na educação formal das entrevistadas. Todas, entretanto, buscaram agregar conhecimentos a partir de cursos, especializações e congressos que se relacionam à sua prática e complementam sua experiência profissional. Tal situação pode constituir um empecilho para recém-graduados que pretendem atuar nesta área, os quais podem até mesmo iniciar o exercício sem ter clareza sobre o tema. Esse cenário confirma a hipótese de que profissionais da saúde vivenciam dificuldades em lidar com pacientes em estado terminal por falta de preparo relativo à sua formação.

As profissionais relatam ainda a existência de certa barreira para lidar com pacientes em estado terminal, levando em conta as suas questões subjetivas e experiências. Entretanto, cabe aqui ressaltar que tais dificuldades, que resultam em uma série de emoções e sentimentos, estão vinculadas à natureza humana. Dessa forma, é possível afirmar que é natural que o profissional crie vínculo com o paciente e sofra junto dele, sendo que isto não deve constituir uma objeção para que ele exerça sua função.

Um outro aspecto que merece ser destacado diz respeito à entrevista com a capelã hospitalar, que foi um ponto-chave durante o desenvolvimento deste artigo, pois nota-se que ainda há um preconceito acerca de profissionais que lidam com a questão espiritual dentro da saúde e ciência. Entretanto, ao longo de sua fala, foram nítidos o comprometimento e a importância de um profissional que articule e defronte com esta temática dentro dos hospitais, não somente com os pacientes e seus familiares, mas com a equipe que atua junto a estes.

Futuros trabalhos podem ser desenvolvidos no intuito de averiguar problematizações que, a princípio, irromperam durante o desenvolvimento deste estudo. Uma delas é discutir as possibilidades de como esta temática - morte e o morrer - pode ser incluída dentro das grades curriculares dos cursos de saúde para que o futuro profissional esteja preparado para lidar com a demanda. Outra sugestão advém do fato de se falar sobre morte com crianças. Em virtude disso, pode-se discutir a relevância de trazer tal tema à tona desde as fases iniciais da vida, para que a morte seja vista como algo natural, como o fim de um ciclo.

Por fim, pontuando-se as limitações presentes nesta pesquisa, é destacado o não acesso a uma diversidade de categorias profissionais, como médicos, terapeutas ocupacionais e nutricionistas, que não estavam presentes no hospital no dia das entrevistas ou que por algum motivo não puderam disponibilizar seu tempo. Também, não foi possível acessar um hospital público, visto que empecilhos não permitiram o contato da equipe com profissionais que nele atuam.

\section{Referências}

Aguiar, I. R., Veloso, T. M. C., Pinheiro, A. K. B., \& Ximenes, L. B. (2006). O envolvimento do enfermeiro no processo de morrer de bebês internados em Unidade Neonatal. Acta Paulista de Enfermagem, 19(2), 131-137. Recuperado de http://www.scielo.br/pdf/ape/ v19n2/a02v19n2.pdf 
Academia Nacional de Cuidados Paliativos (2006). Critérios de qualidade para os cuidados paliativos no Brasil. Rio de Janeiro: Diagraphic Editora. Recuperado de http:// www.rdconsultoria.com.br/Downloads/Educa\%C3\%A7\%C3\%A30\%20Continuada/ Gest\%C3\%A30\%20de\%20Enfermagem/Cuidados\%20Paliativos.pdf

Academia Nacional de Cuidados Paliativos (2009). Manual de cuidados paliativos/Academia Nacional de Cuidados Paliativos. Rio de Janeiro: Diagraphic. Recuperado de http:// www.santacasasp.org.br/upSrv01/up_publicacoes/8011/10577_Manual\%20de\%20 Cuidados\%20Paliativos.pdf

Academia Nacional de Cuidados Paliativos (2012). Manual de cuidados paliativos. (2 ed., s. I). São Paulo: ANCP. Recuperado de www.paliativo.org.br/dl.php?bid=146

Andrade, C. G., Costa, S. F. G., \& Lopes, M. E. L. (2013, set.). Cuidados paliativos: A comunicação como estratégia de cuidado para o paciente em fase terminal. Ciência e Saúde Coletiva, Rio de Janeiro, 18(9), 2523-2530. Recuperado de http://www.scielo.br/pdf/csc/v18n9/ v18n9a06.pdf

Batista, R. S. (2006). Às margens do Aqueronte: Finitude, autonomia, proteção e compaixão no debate bioético sobre a eutanásia (Tese de Doutorado, Fundação Oswaldo Cruz, Escola Nacional de Saúde Pública, Rio de Janeiro). Recuperado de http://www.arca.fiocruz.br/ bitstream/icict/4449/2/248.pdf

Brasil. Ministério da Saúde. (2006). Portaria n. 174 (27 de janeiro). Recuperado de http:// bvsms.saude.gov.br/bvs/saudelegis/gm/2006/prt0174_27_01_2006.html

Costa, Á. P., Poles, K., \& Silva, A. E. (2016). Formação em cuidados paliativos: Experiência de alunos de medicina e enfermagem. Interface (Botucatu), 20(59), 1041-1052. Recuperado de http://www.scielo.br/pdf/icse/v20n59/1807-5762-icse-1807-576220150774.pdf

Falkenberg, M. B., Mendes, T. P. L., Moraes, E. P. \& Souza, E. M. (2014). Educação em saúde e educação na saúde: Conceitos e implicações para a saúde coletiva. Ciência \& Saúde Coletiva, 19 (3), 847-852. Recuperado de http://www.scielo.br/pdf/csc/v19n3/14138123-csc-19-03-00847.pdf

Franco, M. L. P. B. (2012). Análise de conteúdo. (4 ed.). Brasília: Liber Livro.

Gil, A. C. (2010). Como elaborar projetos de pesquisa. (5 ed.). São Paulo: Editora Atlas S. A.

Hermes, H. R. \& Lamarca, I. C. A. (2013, set.). Cuidados paliativos: Uma abordagem a partir das categorias profissionais desaúde. Ciênciae Saúde Coletiva,18(9),2577-2588. Recuperado de http://www.scielo.br/scielo.php?script=sci_arttext\&pid=S1413-81232013000900012\&ln $\mathrm{g}=\mathrm{en} \& \mathrm{nrm}=$ iso.

Mabtum, M. M. \& Marchetto, P. B. (2015). Concepções teóricas sobre a terminalidade da vida. In M. M. Mabtum \& P. B. Marchetto. O debate bioético e jurídico sobre as diretivas antecipadas de vontade (pp. 53-72). São Paulo: Editora Unesp. Recuperado de http:// books.scielo.org/id/qdy26/pdf/mabtum-9788579836602-03.pdf

Marconi, M. A., Lakatos, E. M (2003). Fundamentos da metodologia científica. (5 ed.). São Paulo: Atlas.

Marcucci, F. C. I., Perilla, A. B., Brun, M. M. \& Cabrera, M. A. S (2016). Identificação de pacientes com indicação de cuidados paliativos na Estratégia Saúde da Família: Estudo exploratório. Cadernos de Saúde Coletiva, 24(2), 145-152. Recuperado de http://www. scielo.br/pdf/cadsc/v24n2/1414-462X-cadsc-24-2-145.pdf 
Marcucci, F. C. I. (2016). Identificação e caracterização dos indivíduos com indicação de cuidados paliativos cadastrados na Estratégia Saúde da Família. (Tese de Doutorado, Universidade Estadual de Londrina, Londrina). Recuperado de http://www.bibliotecadigital. uel.br/document/?code=vtls000208832

Martin, L. M. (1998). Eutanásia e distanásia. In S. I. F. Costa, G. Oselka, \& V. Garrafa. Iniciação à bioética (pp. 171-192). Brasília: Conselho Federal de Medicina. Recuperado de http:// portal.cfm.org.br/images/stories/biblioteca/iniciao\%20\%20biotica.pdf

Porto, G.; Lustosa, M. A. (2010). Psicologia Hospitalar e Cuidados Paliativos. Revista SBPH, 13(1), 76-93. Recuperado de http://pepsic.bvsalud.org/pdf/rsbph/v13n1/v13n1a07.pdf

Ramos, K. A. \& Ferreira, A. S. D. (2013, jun). Análise da demanda de medicamentos para uso off label por meio de ações judiciais na Secretaria de Estado de Saúde de Minas Gerais. Revista de Direito Sanitário, 14(1), 98-121. Recuperado de https://www.revistas.usp.br/ rdisan/article/view/56626

Shaughnessy J. J., Zechmeister E. B., \& Zechmeister J. S. (2012). Metodologia de Pesquisa em Psicologia (9a ed.). Porto Alegre: AMGH Editora.

Silveira, M. H., Ciampone, M. H. T., \& Gutierrez, B. A. O. (2014, mar.). Percepção da equipe multiprofissional sobre cuidados paliativos. Revista Brasileira de Geriatria e Gerontologia, 17(1), 7-16. Recuperado de http://www.scielo.br/scielo. php?script=sci_arttext\&pid=S1809-98232014000100007\&Ing=en\&nrm=iso

Siqueira-Batista, R. \& Schramm, F. R. (2004). Eutanásia: pelas veredas da morte e da autonomia. Revista Ciência e Saúde Coletiva, 9(1), 31-41. Recuperado de http://www. scielo.br/pdf/csc/v9n1/19821.pdf

Triviños, A. N. S. (1987). Introdução à pesquisa em ciências sociais: A pesquisa qualitativa em educação. São Paulo: Atlas.

World Health Organization. (2007). Palliative care: Cancer control: Knowledge into actionWHO guide for effective programmes (Module 5). WHO.

Recebido em: 25/10/2018

Última revisão: 1\%/05/2019

Aceito em: 19/06/2019

\section{Sobre as autoras:}

Ana Caroline Birr: Discente do Curso de Psicologia da Universidade da Região de Joinville (Univille). E-mail: birr.carol@gmail.com, Orcid: http://orcid.org/0000-0002-2801-1065

Denise Vieira Taborda: Discente do Curso de Psicologia da Universidade da Região de Joinville (Univille). E-mail: dvt.denise@gmail.com, Orcid: http://orcid.org/0000-0001-7355-9233

Eloisa Capeletto: Discente do Curso de Psicologia da Universidade da Região de Joinville (Univille). E-mail: eloisacapeletto@gmail.com, Orcid: http://orcid.org/0000-0002-9573-2196

Mikeller Freire de Lima: Discente do Curso de Psicologia da Universidade da Região de Joinville (Univille). E-mail: mikeller.freire@gmail.com, Orcid: http://orcid.org/0000-0003-1389-5256

Sofia Cieslak Zimath: Mestre em Administração pela Universidade do Estado de Santa Catarina (Udesc). Docente do curso de Psicologia na Universidade da Região de Joinville (Univille). E-mail: sofiaczimath@yahoo.com.br, Orcid: http://orcid.org/0000-0002-5144-7529 